\title{
Hypermaturity and Immaturity of Personality Profiles in Adolescents ${ }^{\ddagger}$
}

\author{
THEO A. KLIMSTRA*,†, WILLIAM W. HALE III, QUINTEN A. W. RAAIJMAKERS and WIM H. J. MEEUS \\ Research Centre Adolescent Development, Utrecht University, The Netherlands
}

\begin{abstract}
Five-year longitudinal data on a cohort of early to middle adolescents $(N=923)$ and a cohort of middle to late adolescents $(N=390)$ were used to examine the correlates of hypermaturity (i.e. 12-year-olds with a personality profile resembling the profile of an average 20-year-old) and immaturity (i.e. 20-year-olds with a personality profile resembling the profile of an average 12-year-old) of personality. Analyses revealed that girls with high levels of hypermaturity exhibited high levels of internalizing problem behaviour and conflict with parents, while hypermaturity in boys was only associated with internalizing problems. Immature girls had low levels of anxiety and high levels of minor delinquency, whereas immature boys reported low levels of anxiety and high levels of physical maturity. These findings suggest that off-time personality development is an interesting concept deserving further exploration. Copyright (C) 2011 John Wiley \& Sons, Ltd.
\end{abstract}

Key words: five-factor model; normativeness; off-time development; personality; personality profile

\section{INTRODUCTION}

Adolescence is generally regarded as the formative period in a person's life. Individuals undergo tremendous changes towards maturation, both physically (e.g. Petersen, Crockett, Richards, \& Boxer, 1988) and psychosocially (e.g. Erikson, 1950). In the physical domain, an individual grows from a child posture towards an adult posture (Petersen et al., 1988). Psychosocially, adolescents gradually leave their parents' teachings behind in order to start developing their own set of ethics, ideals, and identifications (Erikson, 1950). This process is, for example, reflected in adolescents dealing with identity issues in an increasingly more mature manner (Meeus, Iedema, Helsen, \& Vollebergh, 1999).

These physical and psychosocial changes towards maturation are likely to go hand-in-hand with changes in personality traits. Over the last two decades, a majority of researchers has come to agree that the higher-order structure of personality can be subsumed in five broad traits: The Big Five (Caspi, Roberts, \& Shiner, 2005). The Big Five traits are Extraversion (dominance and activity in interpersonal situations), Agreeableness (willingness to maintain positive and reciprocal relationships with others), Conscientiousness (organizational and motivational aspects of one's behaviour), Emotional Stability (the ability to cope with negative emotions) and Openness to Experience (reflecting how a

*Correspondence to: Theo A. Klimstra, Department School Psychology and Child and Adolescent Development, Catholic University Leuven, TienseStraat 102, bus 3717, 3000 Leuven, Belgium.

E-mail: theoklimstra@wanadoo.nl

${ }^{\dagger}$ Present address: The Department of Psychology, Catholic University Leuven, Belgium.

${ }^{\ddagger}$ The first author is a Postdoctoral Researcher at the Fund for Scientific Research Flanders (FWO). person deals with new information at a personal and experiential level) (Caspi et al., 2005; McCrae \& Costa, 1987). One meta-analysis has revealed increases in mean levels of personality traits (Roberts, Walton, \& Viechtbauer, 2006), and another meta-analysis, on rank-order stability, demonstrated that inter-individual differences become more set with age (Roberts \& DelVecchio, 2000). In a recent empirical study, Klimstra, Hale, Raaijmakers, Branje, and Meeus (2009) had similar findings. In addition, they found substantial gender differences in mean-level change and rank-order stability, with girls displaying high mean levels and rank-order stability at an earlier age than boys did.

A third aspect of personality maturity, profile stability, is less often examined. Profile stability indicates how consistent a rank-ordered set of personality is organized within a single person. For example, an individual might reflect higher mean levels for Agreeableness than for Openness, and higher mean levels for Openness than for Extraversion. If this person would still reflect higher levels of Agreeableness than for Openness and higher levels of Openness than for Extraversion on a subsequent measurement occasion, he or she would have high levels of profile stability. Profile stability is typically examined with $q$ correlations that can range from -1 to +1 , with higher figures representing higher levels of profile stability (e.g. Furr, 2008). At least two studies (Klimstra et al., 2009; Ozer \& Gjerde, 1989) found that profile stability increases from childhood to young adulthood.

Profile stability has been shown to be positively associated with psychological adjustment in several studies (e.g. Asendorpf \& van Aken, 1991; Block, 1971; Donnelan, Conger, \& Burzette, 2007), and therefore it has been described as a marker for psychological maturity (Roberts, Caspi, \& Moffitt, 2001). However, Furr (2008) stated that 
profile stability should not be regarded as a unitary construct, but should be unpacked into several components. He explained that personality profile stability, which he referred to as overall stability, is composed of distinctive stability and several forms of normativeness. Distinctive stability indicates how stable the unique aspects of one's personality are across time. For example, an individual might describe him or herself as having a higher score on Conscientiousness and a lower score on Agreeableness as the average person in a sample does. If this individual would still be above average on Conscientiousness and below the sample mean on Agreeableness on the subsequent measurement occasion, he or she would reflect high distinctive stability (see Furr, 2008, for a similar example). Thus, distinctive stability indicates how consistent an individual diverges from the sample means of a set of trait scores.

Another aspect of profile stability is normativeness. There are several forms of normativeness, starting with within-time normativeness. Within-time normativeness of personality profiles represents the within-person correlation of an individuals' rank-ordered set of personality traits with a rank-ordered set representing a normative personality profile (i.e. a profile based on sample mean scores on all traits). Thus, within-time normativeness indicates whether an individuaĺs set of traits are ordered in a similar way as these traits are ordered in the average person within a sample. In other words, within-time normativeness indicates whether the shape of an individual's personality profile is similar to the shape of the normative personality profile (Furr, 2010). The $q$-correlation reflecting normativeness of personality profiles can range from -1 (i.e. a perfect mismatch between an individual's profile and the normative profile) and 1 (i.e. a perfect match between an individual's profile and the normative profile).

Furr (2008) hypothesized that the positive associations between profile stability that have been found in previous studies were mainly driven by effects of normativeness. Recently, Klimstra, Luyckx, Hale, Goossens, and Meeus (2010a) found evidence for Furr's hypothesis, as distinctive stability turned out to be unrelated to psychological adjustment, whereas within-time normativeness had strong positive associations with self-esteem, and negative associations with depression and delinquency. Thus, individuals with a personality profile that deviates from the average profile tend to display higher levels of problem behaviour symptoms.

The study by Klimstra et al. (2010a) merely demonstrates that people with a personality profile shape that is different from the shape of the profile of the 'average' person display more problem behaviour. Of course, people can differ from the average person in different ways. To deal with this issue, Furr (2008) briefly mentioned an appealing opportunity to put personality profile normativess in a developmental context by calculating two types of across-time normativeness. First, one could assess the degree to which a younger aged individual's personality profile matches the normative profile of an older age cohort. Second, it is possible to calculate the degree to which an older aged individual's profile matches the normative profile of a younger age cohort. These two types of across-time normativeness could be indicative of developmental hypermaturity and immaturity of personality, respectively. Hypermaturity would indicate that one is ahead in personality profile development, whereas immaturity would indicate that one is lagging behind. However, it should be noted that such indices of offtime personality development would merely indicate that the shape of one's personality profile is similar to the shape of the personality profile of a younger (i.e. immaturity) or older (i.e. hypermaturity) individual (Furr, 2008, 2010). The shape of a profile is determined by the relative ordering of traits within a person, and is thus informative on whether an individual scores higher on, for example, Conscientiousness or on Agreeableness. In a similar way, normative profiles are informative on the relative ordering of traits in the average person. Thus, hypermaturity would indicate that an individual's personality traits are ordered in a similar way as those of the average older person, whereas immaturity would indicate that an individual's personality traits are ordered in a similar way as those of an average younger person. Although hypermaturity and immaturity indices are merely informative about the shape of a profile, these indices would provide some insights into off-time personality profile development.

Hypermaturity and immaturity indices should be considered additions to instead of replacements of more classic person-centered approaches to personality, such as the typological approach by Block \& Block (1980). Block and Block's Resilients (individuals well-able to adapt themselves to different situations), Undercontrollers (individuals with stable (overly) low levels of impulse control) and Overcontrollers (individuals with stable (overly) high levels of impulse control) are multidimensional representations of individual differences within (e.g. Asendorpf, Borkenau, Ostendorpf, \& van Aken, 2001) or across (e.g. Klimstra, Hale, Raaijmakers, Branje, \& Meeus, 2010b) time, but make no reference to development as a factor that could affect these individual differences. Putting individual differences in a developmental context is important for personality psychology, as age-graded role expectations have been considered as important 'motors' for normative changes (i.e. changes that are expected to occur at a similar degree for most individuals) in personality (e.g. Roberts, Wood, \& Smith, 2005). Because normative changes tend to occur to a different degree in different personality traits (e.g. Klimstra et al., 2009; Roberts et al., 2006), the shape of a profile composed of these traits also changes as individuals grow older. Indices of hypermaturity and immaturity would be especially useful to assess to what extent individuals are able to keep up with such age-graded normative changes in the shape of a personality profile, and their accompanying social role expectations. Adolescence as a period of substantive changes in role expectations (Erikson, 1950) and, probably consequently, personality (e.g. Klimstra et al., 2009) may be the perfect period to pursue a developmental perspective on personality.

For that reason, we will focus on the correlates of off-time personality development in adolescence. For this purpose, we will employ five-annual wave longitudinal data on a cohort of early to middle adolescents who were 12 years of 
age on average at the first measurement occasion, and a cohort of middle to late adolescents who were 16 years of age on average at the first measurement occasion. As such, an age range from 12 to 20 years is available. Hypermaturity will be operationalized as the degree to which the shape of a profile of a 12-year-old (i.e. the T1 profile of an early to middle adolescent) matches the shape of a normative profile of a 20-year-old (i.e. based on means of Big Five traits of middle to late adolescents at T5). Immaturity reflects the degree to which the shape of a profile of a 20-year-old (i.e. the T5 profile of a middle to late adolescent) matches the shape of a normative profile of a 12-year-old (i.e. based on means of Big Five traits of early to middle adolescents a T1). Thus, we will use data from two cohorts to determine hypermaturity and immaturity of personality. Because previous studies found substantive gender differences in adolescent personality (e.g. Klimstra et al., 2009), we will account for such differences by running analyses for boys and girls, separately. As a result, we will be able to calculate hypermaturity for 468 early to middle adolescent boys and 455 early to middle adolescent girls, and immaturity of personality for 169 middle to late adolescent boys and 221 middle to late adolescent girls.

To examine the correlates of hypermaturity and immaturity of personality, we will correlate the indices reflecting these types of off-time personality profile development with three indicators of adolescent 'storm-and-stress' problem behaviours (Arnett, 1999): (a) mood disruptions (i.e. anxiety and depression), (b) risk behaviour (i.e. delinquency) and (c) conflict with parents (i.e. frequency of conflicts). In an attempt to establish whether being offtime with regard to personality development is related to offtime pubertal development, we will also relate personality hypermaturity and immaturity indices to pubertal status. Because the current study is the first to examine hypermaturity and immaturity, we can only provide tentative hypotheses with regard to their correlates. As adolescents tend to move to a more mature personality with relatively higher levels on favourable personality traits like Agreeableness and Emotional Stability (e.g. Klimstra et al., 2009), being ahead in this process (i.e. hypermaturity) is not expected to be related to problem behaviour. On the other hand, lagging behind (i.e. immaturity) in personality development is expected to be related to problem behaviour. With regard to the relation between pubertal status and offtime personality development, one might at first expect that hypermaturity of personality would be related to being ahead in pubertal development, and that immaturity would be related to lagging behind in pubertal development. However, it is also very well possible that off-time pubertal development and off-time personality development might be largely independent from one another.

\section{METHOD}

\section{Participants}

For this study, we used data from an ongoing longitudinal research project on Conflict And Management Of Relation- ships (CONAMORE; Meeus, Akse, Branje, Ter Bogt, Crommelin, \& Delsing, 2006). The longitudinal sample consisted of 1,313 participants divided into an early to middle adolescent cohort $(n=923 ; 70.3 \%)$ who were 12.4 years of age on average $(S D=.59)$, and a middle to late adolescent cohort $(n=390 ; 29.7 \%)$ with an average age of 16.7 years $(S D=.80)$ during the first wave of measurement. The early to middle adolescent cohort consisted of 468 boys $(50.7 \%)$ and 455 girls $(49.3 \%)$, and the middle to late adolescent cohort consisted of 169 boys (43.3\%) and 221 girls $(56.7 \%)$. Because both age groups were assessed during five consecutive annual measurement waves, a total age range from 12 to 20 years was available. In the current study, we used the first measurement wave of the early to middle adolescent cohort, and the fifth (and final) measurement wave of the middle to late adolescent cohort.

Missing values were estimated in SPSS, using the EMprocedure. Across waves $4.94 \%$ of the data was missing. Little's Missing Completely At Random Test (Little, 1988) revealed a normed $\chi^{2}\left(\chi^{2} / \mathrm{df}\right)$ of 1.20 which according to guidelines by Bollen (1989) indicates a good fit between sample scores with and without imputation.

\section{Procedure}

The participating adolescents were recruited from various high schools in the Province of Utrecht, The Netherlands. Participants and their parents received an invitation letter, describing the research project and goals, and explaining the possibility to decline from participation. More than $99 \%$ of the approached high school students decided to participate. All participants signed the informed consent form. The questionnaires were completed at the participants' own high school, during annual assessments. Confidentiality of responses was guaranteed. Verbal and written instructions were offered. The adolescents received $€ 10$ (approximately US \$13) as a reward for every wave they participated in.

\section{Measures}

\section{Personality}

Personality was assessed with the shortened Dutch version of Goldberg's Big Five Questionnaire (Gerris, Houtmans, Kwaaitaal-Roosen, Schipper, Vermulst, \& Janssens, 1998; Goldberg, 1992). In this instrument, a 7-point likert scale, with a response format ranging from 1 (completely untrue) to 7 (completely true), is used to assess five personality dimensions: Extraversion, Agreeableness, Conscientiousness, Emotional Stability and Openness to Experience. All dimensions are measured with six items each, such as: talkative (Extraversion), sympathetic (Agreeableness), systematic (Conscientiousness), worried (Emotional Stability) and creative (Openness to Experience). Reliability was high across waves, as Cronbach's $\alpha$ for early to middle and middle to late adolescents ranged from .76 to .81 for Extraversion, from .80 to .88 for Agreeableness, from .81 to .92 for Conscientiousness, from .79 to .85 for Emotional Stability and from .74 to .79 for Openness to Experience. 
Because the Dutch version of Goldberg's Big Five Questionnaire has, to the best of our knowledge, not been formally validated in a sample of 12-year-olds, we ran a set of Confirmatory Factor Analyses to establish its validity for this age group. Confirmatory Factor Analyses revealed that a five-factor model provided a much better fit than an alternative one-factor model. Further Confirmatory Factor Analyses revealed measurement invariance of the questionnaire for 12-year-olds when compared to 20-year-olds. Details (e.g. fit statistics) are available from the first author upon request.

\section{Anxiety}

The Screen for Child Anxiety Related Emotional Disorders (SCARED) was used to measure anxiety symptoms. The SCARED is a self-report questionnaire, which is used to measure symptoms of DSM-IV linked anxiety disorders in children and adolescents. It has been shown to be a reliable and valid measure (Birmaher et al., 1997; Muris, Merckelbach, Van Brakel, \& Mayer, 1999; Muris \& Steerneman, 2001). Its factor structure has consistently been replicated among early and middle adolescents, and boys and girls (Hale, Raaijmakers, Muris, \& Meeus, 2005). The SCARED consists of 38 items and contains five subscales: panic disorder symptoms (13 items), social anxiety symptoms (4 items), separation anxiety symptoms (8 items), generalized anxiety symptoms ( 9 items) and school phobia symptoms (4 items). In this study, the composite anxiety score is used, hence, the subscales are not investigated separately. Sample items include 'When frightened, it is hard to breathe', 'I don't like to be with people I don't know', 'I get scared when I sleep away from home', 'I worry about others not liking me' and 'I get headaches or stomach aches when I am at school'. The items are scored on a 3-point scale, ranging from 'hardly ever', 'sometimes' to 'often'. In the current study, Cronbach's $\alpha$ for early to middle and middle to late adolescents ranged from .92 to .95 across waves.

\section{Depression}

Depressive symptoms were measured with the Children's Depression Inventory (CDI; Kovacs, 1985), a self-report questionnaire aimed at screening (subclinical) depressive symptomatology in children and adolescents. This scale has demonstrated convergent and discriminant validity, good internal consistency and adequate test-retest reliability in previous studies (Craighead, Smucker, Craighead, \& Ilardi, 1998; Hodges, 1990). The CDI consists of 27 items (e.g. 'I'm sad all the time'). The items were scored on a 3-point scale, ranging from 1 (false), to 3 (very true). Reliability of the CDI was high across waves for both early to middle and middle to late adolescents as Cronbach's $\alpha$ ranged from .88 to .94 .

\section{Delinquency}

Delinquency was measured with an adapted version of a selfreport questionnaire, measuring the frequency of several minor offences (Baerveldt, van Rossem, \& Vermande, 2003). The use of self-report data is widespread in criminology, and it is a valid instrument when restricted to minor offences (Baerveldt, 2000). Adolescents were asked how many times they had committed 14 minor offences, such as 'being caught by the police for doing something bad' or 'stealing a bike', in the past 12 months. The corresponding 14 items were scored on a 4-point scale, ranging from 1 (never), to 4 (four times or more). The original scale by Baerveldt et al. (2003) also contained items measuring drug use. These items were excluded from the delinquency scale. The slightly modified delinquency scale was reliable across waves in our sample: Reliability was acceptable among early to middle adolescents and middle to late adolescents, as Cronbach's $\alpha$ ranged from .77 to .92 .

\section{Conflict}

The Interpersonal Conflict Questionnaire (Laursen, 1993; Laursen, 1995) was used to measure the frequency of conflicts. Adolescents indicated whether they had had an argument or fight with their fathers and mothers over the past 7 days with regard to 35 issues. A five-point Likert scale was used, ranging from never to often. Sample items are 'manners,' 'privacy,' 'not doing what you are asked to do,' 'homework' and 'being honest.' The last item included the option 'other,' which adolescents could use to fill out an additional conflict topic not covered by the list. Similar to previous studies (e.g. van Doorn, Branje, \& Meeus, 2008) we averaged the 35 items to compute mean scores for conflict with fathers and mothers. Reliability was high for early to middle and middle to late adolescents, with Cronbach's $\alpha$ ranging from .94 to .96 across waves.

\section{Pubertal status}

Pubertal status was measured with one self-reported item adapted from the Perceived Pubertal Timing Scale of the Pubertal Development Scale (Petersen, Crockett, Richards, \& Boxer, 1988), reading 'In comparison with other boys/girls my age, my body develops...'. Adolescents were requested to respond to this item on a five-point Likert scale ranging from 1 (much slower) to 5 (much faster). Pearson test-retest correlations ranged from .67 to .71 for boys, and from .73 to .75 for girls.

\section{Strategy of analyses}

The first step in the current study was to calculate hypermaturity and immaturity indices, using Pearson $q$ correlations. $Q$-correlations have a theoretical range from -1 to 1 , with higher figures indicating higher levels of hypermaturity and immaturity. As such, $q$-correlations can be used as normal continuous variables and can, therefore, be entered into correlation and regression analyses (e.g. Ozer \& Gjerde, 1989; Roberts et al., 2001). Previous studies (e.g. Klimstra et al., 2009) found remarkable gender differences on Big Five personality dimensions. Therefore, we calculated hypermaturity and immaturity indices for boys and girls separately.

To calculate hypermaturity for boys, we first calculated mean scores of 20-year-old boys (i.e. T5 scores of middle to late adolescent boys) on all Big Five dimensions. In the next step, we calculated $q$-correlations between the resulting personality profile of the average 20 -year-old boy (i.e. the 
profile of the average middle to late adolescent boys at T5) with personality profiles of each individual 12-year-old adolescent boy (i.e. early to middle adolescent boys at $\mathrm{T} 1$ ). The $q$-correlation then reflected the degree to which the personality profile of any 12-year-old adolescent boy in our sample matched the personality profile of an average 20year-old boy, and hence reflected the degree of hypermaturity of 12-year-old adolescent boys. This procedure resulted in $468 q$-correlations representing hypermaturity for 12 -year-old boys (range $=-.79$ to .99 ). With a similar procedure, we calculated $q$-correlations representing hypermaturity for 455 twelve-year-old girls. These $q$-correlations ranged from -.81 to 1.00 .

Immaturity for boys was calculated in a similar way. First, mean scores of 12-year-old boys (i.e. T1 scores of early to middle adolescent boys) were calculated for each Big Five dimension, resulting in an average profile of a 12-year-old boy. In the next step, $q$-correlations between the personality profile of an average 12-year-old boy (i.e. the profile of the average early to middle adolescent boy at T1) and each 20-year-old individual boy's (i.e. middle to late adolescent boys at T5) personality profile were assessed. This procedure resulted in $169 q$-correlations (ranging from -.82 to 1.00 ) reflecting the degree to which the personality profile of a 20 -year-old boy matched the profile of an average 12-year-old boy, and therefore indicated the degree of immaturity of a 20 -year-old individual boy. A similar procedure was followed to calculate $q$-correlations representing immaturity (range $=-.55$ to .97 ) for the 221 twenty-year-old girls in our sample.

Correlations of hypermaturity and immaturity of personality with problem behaviour and pubertal status could merely indicate that being different from the average person might be associated with these variables. To account for this, we controlled for within-time normativeness of personality (i.e. the degree to which one's personality profile matches the profile of same-aged peers; see Furr, 2008; Klimstra et al., 2010a). To calculate within-time normativeness for 12-year-old boys, we first determined the mean scores of the 12-year-olds (i.e. T1 scores of early to middle adolescent boys) on the Big Five dimensions. Next, we calculated $q$-correlations between the resulting profile of the average 12-year-old boy (i.e. the profile of the average early to middle adolescent boy at T1) and the personality profiles of each individual 12-year-old boy. This procedure resulted in $468 q$-correlations reflecting within-time normativeness for 12-year-old boys (range $=-87,1.00$ ). In a similar way, we calculated within-time normativeness for 20-yearold boys $(N=169$; range $=-.58, .99), 12$-year-old girls $(N=455 ; \quad$ range $=-.91, .99)$ and 20-year-old girls $(N=221$; range $=-.58, .96)$.

As previously mentioned, $q$-correlations can be used as continuous variables and can therefore be entered into correlation and regression analyses. As such, we assessed partial correlations of hypermaturity with problem behaviour and pubertal status, and of immaturity with problem behaviour and pubertal status as a second step of our strategy of analyses. In these analyses, we controlled for the associations of within-time normativeness with problem behaviour symptoms and pubertal status.

\section{RESULTS}

In order to conclude that personality development is off-time when a 12-year-old displays a personality profile similar to the profile of an average 20-year-old, or the 20-year-old displays a personality profile similar to the profile of an average 12-year-old, one should first examine whether there are dissimilarities between the profile of an average 12-yearold and an average 20-year-old. This turned out to be the case, as the profile similarity between the profile of an average 12 -year-old boy and an average 20 -year-old boy was .78. For girls, the $q$-correlation representing similarity between these two profiles was .64. Because these figures were well below 1.00 , we could proceed to the second step in our examination of the implications of having a hypermature or immature personality profile: the calculation of indices for hypermaturity and immaturity with $q$-correlations. Descriptive statistics for Big Five personality traits (on which our indices of within-time normativeness, hypermaturity and immaturity are based), within-time normativeness, hypermaturity and immaturity indices, problem behaviour and pubertal status are displayed in Table 1, for boys and girls separately. The personality profiles that were used to calculate indices of hypermaturity and immaturity are based upon the mean-level Big Five trait scores presented in this table.

In the next step, we assessed how hypermaturity and immaturity were associated with problem behaviour and pubertal status, using partial correlations. To make sure we dealt with the unique effects of our hypermaturity and immaturity indices, we controlled for the effects of withintime normativeness. Zero-order correlations (in which the effects of within-time normativeness were not controlled for) and partial correlations of hypermaturity and immaturity with problem behaviour and pubertal status (in which the effects of within-time normativeness were controlled for), are depicted in Table 2.

Partial correlations in Table 2 reveal that hypermaturity in early adolescent boys and girls was associated with internalizing problem behaviour, as hypermaturity was positively correlated with levels of anxiety and depression. For girls, higher levels of hypermaturity were additionally associated with higher levels of conflict. Correlations with externalizing problem behaviour and pubertal status did not reach significance.

Higher levels of immaturity were related to lower levels of anxiety and depression, and a more advanced pubertal status in boys. In girls, immaturity was also negatively associated with levels of anxiety, but it was positively associated with levels of delinquency.

\section{DISCUSSION}

In the current study, we explored the correlates of two types of cross-time personality profile normativeness: hypermaturity and immaturity. Overall, our findings suggest that girls were more affected by off-time personality profile development than boys, and that hypermaturity was 
Table 1. Means and standard deviations of boys and girls for Big Five personality traits, hypermaturity, immaturity and problem behaviour

\begin{tabular}{|c|c|c|c|c|}
\hline & \multicolumn{2}{|c|}{ Boys } & \multicolumn{2}{|c|}{ Girls } \\
\hline & $\begin{array}{c}\text { Age } 12 \\
(N=468) M(S D)\end{array}$ & $\begin{array}{c}\text { Age } 20 \\
(N=169) M(S D)\end{array}$ & $\begin{array}{c}\text { Age } 12 \\
(N=455) M(S D)\end{array}$ & $\begin{array}{c}\text { Age } 20 \\
(N=221) M(S D)\end{array}$ \\
\hline \multicolumn{5}{|l|}{ Big Five traits } \\
\hline Extraversion & $4.87(.98)$ & $4.93(1.13)$ & $4.95(1.05)$ & $4.77(1.18)$ \\
\hline Agreeableness & $4.93(1.16)$ & $5.68(.60)$ & $5.20(.97)$ & $5.73(.55)$ \\
\hline Conscientiousness & $4.05(1.13)$ & $4.32(1.18)$ & $4.23(1.09)$ & $4.71(1.19)$ \\
\hline Emotional stability & $4.70(1.16)$ & $4.77(.99)$ & $4.57(1.08)$ & $4.24(1.04)$ \\
\hline Openness & $4.38(1.14)$ & $4.95(.85)$ & $4.40(1.01)$ & $4.87(.86)$ \\
\hline Normativeness & $.45(.46)$ & $.55(.33)$ & $.43(.45)$ & $.54(.28)$ \\
\hline Hypermaturity & $.40(.40)$ & - & $.43(.38)$ & - \\
\hline Immaturity & - & $.43(.47)$ & - & $.38(.38)$ \\
\hline \multicolumn{5}{|l|}{ Problem behaviour } \\
\hline Anxiety & $1.30(.31)$ & $1.19(.20)$ & $1.33(.26)$ & $1.32(.26)$ \\
\hline Depression & $1.16(.29)$ & $1.11(.15)$ & $1.16(.21)$ & $1.19(.22)$ \\
\hline Delinquency & $1.28(.49)$ & $1.14(.25)$ & $1.11(.32)$ & $1.04(.08)$ \\
\hline Conflict & $1.77(.50)$ & $1.44(.41)$ & $1.64(.46)$ & $1.29(.35)$ \\
\hline Pubertal status ${ }^{\mathrm{a}}$ & $3.04(.66)$ & $3.07(.74)$ & $2.98(.67)$ & $3.06(.67)$ \\
\hline
\end{tabular}

Note: Hypermaturity represents a $q$-correlation of actual personality profiles of 12 -year olds with the average personality profile of a 20 -year old individual. Immaturity reflects a $q$-correlation of actual personality profiles of 20 -year olds with the average personality profile. Normativeness is within-time normativeness.

${ }^{\mathrm{a}}$ Pubertal status was not measured on T5 (i.e. the measurement wave at which we constructed our immaturity variable). Therefore, we included T4 pubertal status.

Table 2. Partial correlations (controlled for within-time normativeness) between hypermaturity and immaturity, and problem behaviour for adolescent boys and girls

\begin{tabular}{|c|c|c|c|c|c|c|c|c|c|c|}
\hline \multirow[b]{2}{*}{ Boys } & \multicolumn{2}{|c|}{ Anxiety } & \multicolumn{2}{|c|}{ Depression } & \multicolumn{2}{|c|}{ Delinquency } & \multicolumn{2}{|c|}{ Conflict } & \multicolumn{2}{|c|}{ Pubertal status ${ }^{a}$} \\
\hline & & & & & & & & & & \\
\hline Hypermaturity $(N=468)$ & $.16^{* *}$ & $(-.03)$ & $.10^{*}$ & $(-.02)$ & -.04 & $(-.06)$ & .03 & $(.01)$ & -.05 & $(-.03)$ \\
\hline Immaturity $(N=169)$ & $-.29^{* * *}$ & $\left(-.26^{* * *}\right)$ & $-.16^{*}$ & $(-.13)$ & .12 & $(.09)$ & -.04 & $(.01)$ & $.19^{*}$ & $(.13)$ \\
\hline \multicolumn{11}{|l|}{ Girls } \\
\hline Hypermaturity $(N=455)$ & $34^{* * *}$ & $\left(.23^{* * *}\right)$ & $.35^{* * *}$ & $\left(.26^{* * *}\right)$ & -.07 & $(-.06)$ & $.14^{* *}$ & $\left(.14^{* *}\right)$ & -.03 & $(-.01)$ \\
\hline Immaturity $(N=221)$ & $-.33^{* * *}$ & $\left(-.25^{* * *}\right)$ & -.12 & $(-.06)$ & $.22^{* *}$ & $\left(.22^{* *}\right)$ & -.02 & $(.01)$ & .06 & $(.07)$ \\
\hline
\end{tabular}

Note: ${ }^{*} p<.05 ;{ }^{* *} p<.01{ }^{* * *} p<.001$. Zero-order correlations are presented between parentheses.

a Pubertal status was not measured on T5 (i.e. the measurement wave at which we constructed our immaturity variable). Therefore, the correlation between pubertal status and immaturity is a correlation between T4 pubertal status and T5 immaturity.

positively associated with internalizing problems and conflict, whereas immaturity was related to lowered levels of anxiety in girls and boys, externalizing problems in girls, and lowered levels of depressive symptoms and a more advanced pubertal status in boys.

Contrary to our tentative expectations, hypermaturity was associated with problems in both boys and girls. Girls who reflected high levels of developmental hypermaturity (i.e. displaying a personality profile resembling the profile of an average a 20 -year-old at age 12) exhibited several problems. They were more anxious and depressed, and reported more conflicts with their parents. Hypermaturity in boys was also positively associated with internalizing problems (i.e. anxiety and depression), but unlike girls boys did not exhibit higher levels of conflict with parents when they displayed hypermaturity of personality. Although there were no significant associations between hypermaturity and pubertal timing, there appears to be some similarity between our findings and those that have been obtained in studies regarding early pubertal timing (for an overview, see Graber, 2003). These studies suggest that facing the physical transitions accompanying pubertal development (i.e. rapid growth spurt, menarche) well before one's peers do may results in psychosocial problems, because early maturing adolescents may simply be less prepared for the consequences of obtaining and adult-like posture (e.g. BrooksGunn, Petersen, \& Eichorn, 1985). Thus, they may elicit responses from others (e.g. parents, teachers and peers) for which they are not psychologically ready. On the contrary, individuals with a hypermature personality profile may have higher levels of psychological maturity than their physics would suggest. For that reason, individuals with a hypermature personality may be treated in a way that may correspond with their physical maturity, but may not correspond with their levels of psychological maturity. In other words, they may feel like they are treated childishly. If individuals feel like they are being treated in an ageinappropriate manner, they may experience a poor stageenvironment fit which could consequently lead to negative outcomes, such as lower levels of self-esteem (Eccles et al., 1993). This mechanism could possibly explain why an asset such as a hypermature personality (which might at first seem 
a positive characteristic) may, contrary to our tentative hypotheses, turn out to be a negative asset.

Our results strongly suggest that girls experience more negative consequences of hypermaturity than boys do, as associations between hypermaturity and internalizing problem behaviour (i.e. depression and anxiety) were much stronger in girls than in boys. This could be due to the fact that on average girls tend to be somewhat ahead on boys in the maturation of personality (Klimstra et al., 2009). As a result, hypermature boys are quite likely to at least find some same-aged girls with a similar level of maturity. Hypermature girls are less likely to find same-aged peers, either boys or girls, with a similar level of psychological (i.e. personality) maturity. Therefore, they may experience the previously described poor stage-environment fit to a stronger extent than hypermature boys would. As a poor stageenvironment fit has been associated with lower levels of selfesteem (Eccles et al., 1993), this could possibly explain why hypermaturity has stronger associations with internalizing problems in girls than in boys.

Hypermature girls, but not hypermature boys, also experience elevated levels of conflict with parents. It has been shown that connectedness plays a central role in psychological development of adolescent girls, but to a much lesser extent in adolescent boys (e.g. Geuzaine, Debry, \& Liesens, 2000). Accordingly, girls have been found to communicate more with their parents when compared to boys (Keijsers, Frijns, Branje, \& Meeus, 2010). Thus, these studies suggest that girls have more verbal interactions with their parents. It is in these verbal interactions where hypermature girls may be most prone to feel like they are treated in a childish manner (i.e. experience a poor stageenvironment fit). This could lead to discontent with the relationship with their parents. An obvious way to express this discontent is to engage in more conflicts with parents. Hypermature boys, on the other hand, engage in less communication with their parents, and hence may be less likely to feel like they are treated in an age-inappropriate manner. For that reason, they may be less likely to experience discontent with regard to the relationship with their parents.

Immaturity of personality was associated with lower levels of anxiety in both boys and girls. For the immature boys in the current study, these low levels of anxiety were accompanied by low levels of depression, but a more advanced pubertal status. Thus, a lack of psychological maturity seems to go together with physical hypermaturity. This, at first glance perhaps counter intuitive finding, might be explained by the effects of the hormone testosterone. Testosterone is responsible for physical changes in puberty for men (e.g. Styne, 1994), but it is also associated with behaviour that could easily be considered immature, namely non-aggressive risk taking (Vermeersch, T'Sjoen, Kaufman, $\&$ Vincke, 2008). Non-aggressive risk taking is not directly measured in the current study, but the lowered levels of anxiety among boys with an immature personality could suggest some proneness to engage in such activities. Thus, although the individual correlates of immaturity of personality in boys indicate that it is a positive asset, the pattern of associations across correlates suggest that there could be some downsides that were not measured in the current study. Therefore, future research could examine linkages of immaturity of personality with testosterone levels and non-aggressive risk-taking in boys.

Findings of the present study strongly suggest that the lowered levels of anxiety exhibited by immature girls are even less likely to just be a positive thing, as they are accompanied by higher levels of delinquency. Considering that a previous study (Shaw, Gilliom, Ingoldsby, \& Nagin, 2003) found associations between externalizing problems in adolescence and a pathological lack of anxiety (i.e. fearlessness), immature girls' low levels of anxiety could also be indicative of some sort of fearlessness which could, in turn, explain their higher levels of delinquency. An explanation for immature girls' high levels of minor delinquency can also be derived from studies on general personality development. Klimstra et al. (2009) showed that girls tend to mature earlier with regard to personality than boys. As a result, the girls that do lag behind when compared to the average girls may be at the same stage of personality development as an average boy. In other words, immature girls might simply be more like boys. In the current study (see Table 1) and in general (Arnett, 1999), boys tend to display higher levels of delinquency than girls. As such, lagging behind in personality development (i.e. being more like an adolescent boy) could very well result in being more delinquent for adolescents girls.

\section{Limitations}

Although the present study provides a novel perspective on off-time personality development, several limitations should be recognized. First of all, our indices of hypermaturity and immaturity only provide a glance at what the consequences of being ahead or lagging behind normative developmental trends in personality could be. In other words, conceptualizing hypermaturity as younger individuals having a personality profile resembling the typical profile of an older individual, and immaturity as older individuals having a personality profile resembling the typical profile of a younger individual, only provides a rough estimate of what the consequences of off-time personality development could be. More specifically, we only focused on hypermaturity and immaturity in personality profile change, and not on other indicators of personality change such as mean-level change and rank-order stability (e.g. Klimstra et al., 2009; Roberts et al., 2001).

Second, we only focused on one specific aspect of personality profiles: Their shape (e.g. the specific pattern of scores across the Big Five dimensions). Although this could be perceived as a limitation, shape has been described as the psychologically most meaningful aspect of a personality profile (Furr, 2010).

A third limitation concerns the number of measurement occasions of hypermaturity and immaturity. Personality traits do change during adolescence (e.g. Klimstra et al., 2009), but a large interval between measurement occasions is needed to obtain sufficiently different personality profiles to calculate hypermaturity and immaturity. Between ages 12 
and 16, there is, for example, very little change in boys' personality traits, which implies that the personality profile of an average 12-year-old boy is almost identical to the average personality profile of a 16-year old boy. In such cases, a 16-year-old boy reflecting a profile strongly resembling the profile of an average 12-year-old boy cannot be considered immature. Nevertheless, future studies should try to get multiple measurement occasions of hypermaturity and immaturity in order to investigate stability and change in these two facets of personality profiles, and to examine what variables are predictive of, or are predicted by hypermaturity and immaturity.

Fourth, we used data from two cohorts to calculate hypermaturity and immaturity indices. That is, we correlated the profile of an average early to middle adolescent at T1 with profiles of individual middle to late adolescents at T5 to calculate immaturity, and correlated profiles of individual early to middle adolescents with the profile of an average middle to late adolescent at T5. As such, cohort effects (see Twenge, 2000, 2001, for a discussion of cohort effects) might be somewhat confounded with our hypermaturity and immaturity indices. Ideally, hypermaturity and immaturity indices should be calculated using data from one single longitudinally examined cohort.

A final potential limitation concerns the use of adolescent self-reports. The use of self-reports implies that our findings reflect correlates of hypermaturity and immaturity of an adolescents self-perceived personality profile. Although the psychometrics of self-reports of adolescent personality have been shown to be accurate (Soto, John, Gosling, \& Potter, 2008), it would still be interesting to examine if hypermaturity and immaturity indices based on other-reported personality data yield the same conclusions.

\section{CONCLUSION}

Despite these potential limitations, the present study provides a first glance into what the correlates of hypermaturity and immaturity of personality profiles in adolescent boys and girls could be. Our analyses revealed that hypermature boys and girls reflect internalizing problems, whereas hypermature girls additionally exhibited high levels of conflict with parents. Both immature boys and girls reflected lower levels of anxiety than their less immature counterparts. For girls, immaturity was additionally associated with high levels of externalizing problems (i.e. delinquency). These findings underscore the potential importance of examining causes and consequences of offtime personality profile development, and the role of gender in these processes.

\section{REFERENCES}

Arnett, J. J. (1999). Adolescent storm and stress, reconsidered. American Psychologist, 54, 317-326.
Asendorpf, J. B., \& van Aken, M. A. G. (1991). Correlates of the temporal consistency of personality patterns in childhood. Journal of Personality, 59, 689-703.

Asendorpf, J. B., Borkenau, P., Ostendorf, F., \& van Aken, M. A. G. (2001). Carving personality description at its joints: Confirmation of three replicable personality prototypes for both children and adults. European Journal of Personality, 15, 169198.

Baerveldt, C. (2000). Pupil's networks in high schools: Network sampling, program and some results from a theory-oriented research project on petty crime of pupils. Paper presented at the 2nd International Network Sampling Workshop, Maastricht, The Netherlands (March 2-4).

Baerveldt, C., van Rossem, R., \& Vermande, M. (2003). Pupils' delinquency and their social networks: A test of some network assumptions of the ability and inability models of delinquency. The Netherlands Journal of Social Sciences, 39, 107-125.

Birmaher, B., Khetarpal, S., Brent, D., Cully, M., Balach, L., Kaufman, J., et al. (1997). The screen for child anxiety related emotional disorders (scared): Scale construction and psychometric characteristics. Journal of the American Academy of Child and Adolescent Psychiatry, 36, 545-553.

Block, J. (1971). Lives through time. Berkeley, CA: Bancroft Books.

Block, J. H., \& Block, J. (1980). The role of ego-control and egoresiliency in the organization of behavior. In W. A. Collins (Ed.), Development of cognition, affect, and social relations, (Vol. 13, pp. 39-101). Hillsdale: Lawrence Erlbaum Associates.

Bollen, K. (1989). Structural equations with latent variables. New York: Wiley.

Brooks-Gunn, J., Petersen, A. C., \& Eichorn, D. (1985). The study of maturational timing effects in adolescence. Journal of Youth and Adolescence, 14, 149-161.

Caspi, A., Roberts, B. W., \& Shiner, R. L. (2005). Personality development: Stability and change. Annual Review of Psychology, 56, 453-484.

Craighead, W. E., Smucker, M. R., Craighead, L. W., \& Ilardi, S. S. (1998). Factor analysis of the children's depression inventory in a community sample. Psychological Assessment, 10, 156-165.

Donnelan, M. B., Conger, R. D., \& Burzette, R. G. (2007). Personality development from late adolescence to young adulthood: Differential stability, normative maturity, and evidence for the maturity-stability hypothesis. Journal of Personality, 75, 237-264.

Eccles, J. S., Midgley, C., Wigfield, A., Buchanan, C. M., Reuman, D., Flanagan, C., et al. (1993). Development during adolescence: The impact of stage-environment fit on young adolescents' experience in schools and in families. American Psychologist, 48, 90-101.

Erikson, E. H. (1950). Childhood and society. New York: Norton.

Furr, R. M. (2008). A framework for profile similarity: Integrating similarity, normativeness, and distinctiveness. Journal of Personality, 76, 1267-1316.

Furr, R. M. (2010). The double-entry intraclass xorrelation as an index of profile similarity: Meaning, limitations, and alternatives. Journal of Personality Assessment, 92, 1-15.

Gerris, J. R. M., Houtmans, M. J. M., Kwaaitaal-Roosen, E. M. G., Schipper, J. C., Vermulst, A. A., \& Janssens, J. M. A. M. (1998). Parents, adolescents and young adults in dutch families: A longitudinal study. Nijmegen: Institute of Familiy Studies University of Nijmegen.

Geuzaine, C., Debry, M., \& Liesens, V. (2000). Separation from parents in late adolescence: The same for boys and girls? Journal of Youth and Adolescence, 29, 79-91.

Goldberg, L. R. (1992). The development of markers for the big-five factor structure. Psychological Assessment, 4, 26-42.

Graber, J. A. (2003). Puberty in context. In C. Hayward (Ed.), Gender differences at puberty. New York: Cambridge University Press.

Hale, III W. W., Raaijmakers, Q. A. W., Muris, P., \& Meeus, W. H. J. (2005). Psychometric properties of the screen for child anxiety 
related emotional disorders in the general adolescent population. Journal of the American Academy of Child and Adolescent Psychiatry, 44, 283-290.

Hodges, K. (1990). Depression and anxiety in children: A comparison of self-report questionnaires to clinical interview. Psychological Assessment, 2, 367-381.

Keijsers, L., Frijns, T., Branje, S. J. T., \& Meeus, W. (2010). Developmental links of adolescent disclosure, parental solicitation, and control with delinquency: Moderation by parental support. Developmental Psychology, 45, 1314-1327.

Klimstra, T. A., Hale, III WW., Raaijmakers, Q. A. W., Branje, S. J. T., \& Meeus, W. H. J. (2009). Maturation of personality in adolescence. Journal of Personality and Social Psychology, 96, 898-912.

Klimstra, T. A., Luyckx, K., Hale, III W. W., Goossens, L., \& Meeus, W. H. J. (2010a). Longitudinal associations between personality profile stability and adjustment in college students: Distinguishing among overall stability, distinctive stability, and within-time normativeness. Journal of Personality, 78, 11631184.

Klimstra, T. A., Hale, W. W., Raaijmakers, Q. A. W., Branje, S. J. T., \& Meeus, W. H. J. (2010b). A developmental typology of adolescent personality. European Journal of Personality, 24, 309-323.

Kovacs, M. (1985). The children's depression, inventory (CDI). Psychopharmacology Bulletin, 21, 995-998.

Laursen, B. (1993). The perceived impact of conflict on adolescent relationships. Merrill-Palmer Quarterly, 39, 535-550.

Laursen, B. (1995). Conflict and social interaction in adolescent relationships. Journal of Research on Adolescence, 5, 55-70.

Little, R. (1988). A test of missing completely at random for multivariate data with missing values. Journal of the American Statistical Association, 83, 1198-1202.

McCrae, R. R., \& Costa, P. T. (1987). Validation of the five-factor model of personality across instruments and observers. Journal of Personality and Social Psychology, 52, 81-90.

Meeus, W. H. J., Iedema, J., Helsen, M., \& Vollebergh, W. (1999). Patterns of adolescent identity development: Review of literature and longitudinal analysis. Developmental Review, 19, 419-461.

Meeus, W. H. J., Akse, J., Branje, S. J. T., Ter Bogt, T. F. M., Crommelin, P. M., Delsing, M. J. M. H. et al. (2006). Codebook of the research project conflict and management of relationships (conamore). Unpublished manuscript, Utrecht University, The Netherlands, 2006.

Muris, P., \& Steerneman, P. (2001). The revised version of the screen for child anxiety related emotional disorders (SCARED$\mathrm{R})$ : First evidence for its reliability and validity in a clinical sample. British Journal of Clinical Psychology, 40, 35-44.

Muris, P., Merckelbach, H., Van Brakel, A., \& Mayer, B. (1999). The revised version of the screen for child anxiety related emotional disorders (SCARED-R): Further evidence for its reliability and validity. Anxiety, Stress and Coping, 12, 411425.

Ozer, D. J., \& Gjerde, P. F. (1989). Patterns of personality consistency and change from childhood through adolescence. Journal of Personality, 57, 483-507.

Petersen, A. C., Crockett, L., Richards, M., \& Boxer, A. (1988). A self-report measure of pubertal status: Reliability, validity, and initial norms. Journal of Youth and Adolescence, 17, 117133.

Roberts, B. W., \& DelVecchio, W. F. (2000). The rank-order consistency of personality traits from childhood to old age: A quantitative review of longitudinal studies. Psychological Bulletin, 126, 3-25.

Roberts, B. W., Caspi, A., \& Moffitt, T. E. (2001). The kids are alright: Growth and stability in personality development from adolescence to adulthood. Journal of Personality and Social Psychology, 81, 670-683.

Roberts, B. W., Wood, D., \& Smith, J. L. (2005). Evaluating five factor theory and social investment perspectives on personality trait development. Journal of Research in Personality, 39, 166184.

Roberts, B. W., Walton, K. E., \& Viechtbauer, W. (2006). Patterns of mean-level change in personality traits across the life course: A meta-analysis of longitudinal studies. Psychological Bulletin, $132,1-25$.

Shaw, D. S., Gilliom, M., Ingoldsby, E. M., \& Nagin, D. S. (2003). Trajectories leading to school-age conduct problems. Developmental Psychology, 39, 189-200.

Soto, C. J., John, O. P., Gosling, S. D., \& Potter, J. (2008). The developmental psychometrics of big five self-reports: Acquiescence, factor structure, coherence, and differentiation from ages 10 to 20. Journal of Personality and Social Psychology, 94, 718-737.

Styne, D. M. (1994). Physiology of puberty. Hormone Research, 41, 3-6.

Twenge, J. M. (2000). The age of anxiety? Birth cohort change in anxiety and neuroticism, 1952-1993. Journal of Personality and Social Psychology, 79, 1007-1021.

Twenge, J. M. (2001). Birth cohort changes in extraversion: A crosstemporal meta-analysis, 1966-1993. Personality and Individual Differences, 30, 735-748.

van Doorn, M. D., Branje, S. J. T., \& Meeus, W. H. J. (2008). Conflict resolution in parent-adolescent relationships and adolescent delinquency. Journal of Early Adolescence, 28, 503-527.

Vermeersch, H., T’Sjoen, G., Kaufman, J.-M., \& Vicke, J. (2008). The role of testosterone in aggresive and non-aggressive risktaking in adolescents boys. Hormones and Behavior, 53, 463471 . 